\title{
XXXII. On the relationship between the viscosity, density, and temperature of salt solutions
}

\section{W.J. Walker B.Sc.}

To cite this article: W.J. Walker B.Sc. (1914) XXXII. On the relationship between the viscosity, density, and temperature of salt solutions, Philosophical Magazine Series 6, 27:158, 288-297, DOI: $10.1080 / 14786440208635091$

To link to this article: http://dx.doi.org/10.1080/14786440208635091

曲 Published online: 08 Apr 2009.

Submit your article to this journal $₫$

Џ Article views: 3

Q View related articles $₫$ 


\section{Summary.}

The amount of light given by the unstriated discharge and by the arc indicates that the rate at which ions recombine in these forms of discharge varies as the first power of the current, while the equations usually assumed for discharge through gases would lead us to expect that this rate varies as the square of the current. This is explained by assuming that approximately all of the current is carried by electrons and not by ions of molecular size, and that the great majority of the electrons combine first with molecules and afterwards with positive ions.

The fact that the electric force in this form of discharge is a linear function of the pressure of the gas is explained by assuming that the ionization is caused by the impact of the more rapidly moving electrons on the molecules, and that but few of the collisions between electrons and molecules result either in ionization or in recombination, the greater number resulting in no permanent change in either electrons or molecules.

The fact that the electric force decreases slightly when the current is increased, is explained by the added assumption that the potential difference through which an electron must go in order to ionize is smaller with larger currents than with small ones.

Colgate University, October, 1913.

XXXII. On the Relationship between the Viscosity, Density, and Temperature of Salt Solutions. By W. J. WaLKer, B.Se., Carnegie Research Scholar, University College, Dundee*.

\section{[Plate IV.]}

TWHE following notes are derived from the results of 1 experiments carried out at the suggestion of Professor A. H. Gibson in connexion with tests on the resistance to flow of brine solutions through pipes of different diameters. The solutions were of sodium chloride and calcium chloride. The primary object of the experiments was the de:ermination of "the kinematic coefficient of viscosity," or the ratio viscosity/density. Absolute values of the viscosity were obtained by means of the apparatus shown in fig. 1 .

Reservoir A was used to maintain a constant head of about

* Communicated by the Author. 
$18 \mathrm{~cm}$. in vessel $\mathrm{B}$. Discharge from the latter vessel took place through a glass tube $O$ of small bore and $71.5 \mathrm{~cm}$. in length. After the completion of the experiments, the diameter of the tube was ascertained by breaking it up into

Fig, 1,

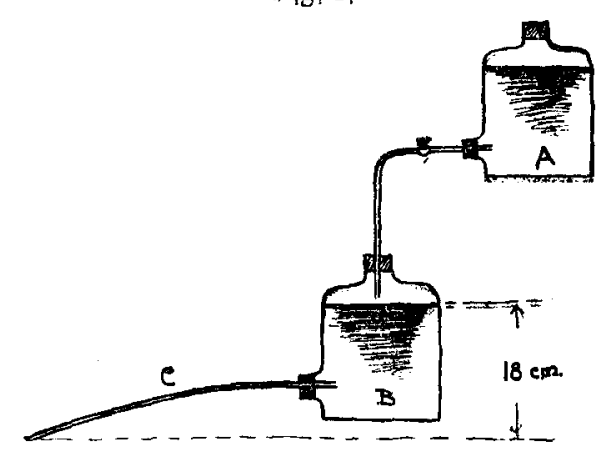

pieces varying from $2 \mathrm{~cm}$. to $3 \mathrm{~cm}$. in length and measuring the diameters by means of a microscope furnished with micrometer eyepieces. The mean of these results gave $.2590 \mathrm{~cm}$. as the tube diameter. In oalculating the viscosities the value $\frac{1,5 \mathrm{~V}^{2}}{2 g}$ was subtracted from the measured
head.

The relationship between the pereentage of salt in the solution and its density was measured by means of a Mohr specifio gravity balance, with the following results in the case of sodium ohloride :-

\begin{tabular}{|c|c|}
\hline \multicolumn{2}{|c|}{ Ternperature $=60^{\circ} \mathrm{F}}$. \\
\hline Percentage Solution. & Specific Gravity. \\
\hline 0 & 1.000 \\
6 & 1.042 \\
12 & 1.088 \\
18 & 1.134 \\
24 & 1.165 \\
28 & 1.198 \\
\hline
\end{tabular}

Note--Percentages reckoned as parts of salt in 100 parts of solution. Phil. Mag. S. 6. Vol. 27. No. 158. Feb. 1914. 


\section{Mr. W. J. Walker : Relationship between Viscosity,}

From these figures it appears that the specific gravity increases uniformly with the percentage of salt in the solution until this attains a value of about 20 per cent. After this point the rate of increase in specific gravity diminishes. This is probably due to the fact in the stronger brines, solution was not complete but that some of the material was held in suspension.

As a check on the accurncy of the viscosity apparatus, this was used to determine the viscosity of water at $62^{\circ} \cdot 3 \mathrm{~F}$. The mean value obtained was 00002265 in F.P.S. units as against Poisenille's value of $\cdot 0000227$. This result gives an assurance that experiments have been carried out with a fair degree of accuracy. The results of one series of experiments on each solution are given below, the sodium chloride series being carried out at a temperature of $62^{\circ} .5 \mathrm{~F}$. and the calcium chloride series at a temperature of $63^{\circ} \mathrm{F}$. An empirical formula was deduced for the sodium chloride series before the calcium chloride series was carried out and is given here:

$$
\mu=\cdot 00002265+\cdot 0000428(\rho-1)+\cdot 000228(\rho-1)^{2} .
$$

This gives in F.P.S. units results practically identical with experimental values.

\begin{tabular}{|c|c|c|c|c|c|}
\hline \multicolumn{3}{|c|}{ Sodium Ohloride $62^{\circ} .5 \mathrm{~F}$. } & \multicolumn{3}{|c|}{ Calcium Chloride $63^{\cap} \mathrm{F}$. } \\
\hline o. & $\mu$ & $\frac{\mu}{\rho}$. & $\rho$. & $\mu$. & $\frac{\mu}{\rho}$. \\
\hline $1 \cdot 000$ & .00002265 & 1.000 & ]$\cdot 000$ & .00002248 & .993 \\
\hline $1 \cdot 008$ & .00002300 & 1.009 & 1.0188 & .00002358 & 1.022 \\
\hline 1.015 & $\cdot 00002335$ & 1016 & 1.054 & $\cdot 00002586$ & 1.083 \\
\hline $1 \cdot 025$ & $.0000 \geqslant 380$ & 1.025 & 1.063 & .00002660 & $1 \cdot 106$ \\
\hline $1 \cdot 037$ & $0000 \div 445$ & 1.041 & $1 \cdot 084$ & .00002855 & $1 \cdot 163$ \\
\hline $\mathrm{l} \cdot 058$ & $.0000 \div 548$ & 1.063 & $1 \cdot 1029$ & $\cdot 00003020$ & 1.210 \\
\hline 1.065 & .00002580 & $1 \cdot 07 l$ & $1 \cdot 115$ & $\cdot 000013170$ & 1.256 \\
\hline 1.078 & $\cdot 0100 \div 685$ & $1 \cdot 100$ & $1 \cdot 130$ & $\cdot 00003318$ & $1 \cdot 295$ \\
\hline 1.095 & $\cdot 00002790$ & $1 \cdot 126$ & $1 \cdot 149$ & $\cdot 00003555$ & $1 \cdot 365$ \\
\hline $1 \cdot 115$ & $\cdot 00003035$ & $1 \cdot 165$ & $1 \cdot 165$ & 00003800 & 1.425 \\
\hline $1 \cdot 142$ & .010003250 & 1.255 & $1 \cdot 184$ & 00004180 & 1.523 \\
\hline $1 \cdot 170$ & .000036อิ5 & 1.378 & $1 \cdot 2078$ & 00005060 & $1.8 \overline{50}$ \\
\hline
\end{tabular}

Note. $-\frac{\mu}{\rho}$ is bere taken relative to water at $62^{\circ} .5 \mathrm{~F}$.

The curves for these solutions showing the relation between viscosity and density are given in fig, 2 (Pl. IV.).

It was intended at first to deduce an empirical formula for 
the calcium chloride series, but on plotting the curves as shown, their appearance suggested an inquiry which led to the following interesting discovery of a relation between viscosity and density whioh does not appear hitherto to have been noticed.

In the Phil. Mag.* Ramsay and Young published a law connecting temperatures at whioh different saturated vapours have the same vapaur pressure. Porter, in the same magazine $\mathrm{H}$, showed that if $\frac{\mathrm{T}}{\mathrm{T}_{0}}$ be plotted against $\mathrm{T}$ where $\mathrm{T}$ and $\mathrm{T}_{0}$ are temperatures of two liquids having the same vapour pressure or the same viscosity at these temperatures, then a straight line will be obtained. From this he deduced that Ramsay and Young's law is accurately true if

$$
\begin{aligned}
f(p) & =\mathrm{A}-\frac{\mathrm{B}}{\mathrm{T}} \\
\text { or } \quad \mathrm{F}(\mu) & =a-\frac{b}{\mathrm{~T}} .
\end{aligned}
$$

Porter showed the latter law to hold for two suoh dissimilar substances as mercury and water. Now in the cases given of sodium and calcium chloride it was found that if $\frac{\mu}{\mu_{0}}$ be plotted against $\mu$ where $\mu$ and $\mu_{0}$ are viscosities at similiar densities, an approximate straight line was abtained, indioating the relationship

$$
\mathrm{F}(\rho)=\mathrm{A}-\frac{\mathrm{B}}{\mu} \cdot, \cdot \cdot \cdot \cdot \cdot
$$

In order to eliminate one of these constants this was thrown into the form

$$
\mathrm{F}^{\prime}(\rho-1)=\mathrm{A}-\frac{\mathrm{B}}{\mu}, \cdot . \cdot, \cdot .
$$

When $\rho=1$ we get $\quad \mathrm{B}=\mu^{\prime} \mathrm{A}$,

where $\mu^{\prime}$ is the viscosity of water at temperature considered.

(2) then becomes

$$
\mathrm{F}^{\prime}(\rho-1)=\mathrm{A}\left(1-\frac{\mu^{\prime}}{\mu}\right) .
$$

* Jan. 1886.

† June 1907 and June 1912.

$\mathrm{U} 2$ 
292 Mr. W. J. Walker : Relationship between Viscosity,

Tentatively, it was found that $F^{\prime}(\rho-1)$ was of the form $(\rho-1)^{n}$ where " $n$ " lay between 1 and 2 for both solutions.

On plotting $\log (\rho-1)$ against $\log \left(1-\frac{\mu^{\prime}}{\mu}\right)$ practically straight lines are obtained in ench case, as shown in fig. 3 .

The values for " $n$ " for these two lines as drawn are 1.038 and 1.055 for sodium and calcium chloride respectively.

In the Smithsonian Tables (1908) figures are given showing the relation between viscosity and density at temperatures $10^{\circ}, 30^{\circ}$, and $50^{\circ} \mathrm{C}$. for sodium and ealcium chloride solutions. It was thought desirable to find how " $n$ " and "A " varied with temperature, so experiments were carried out at temperatures ranging from $0^{\circ}$ to $100^{\circ} \mathrm{C}$. on the sodium chloride solutions. The intermediate figures agreed well with the Smithsonian tigures, except that at $30^{\circ} \mathrm{C}$. the Smithsonian figures were slightly higher. In the case of the calcium solutions the experiments were only carried out at the lowest temperature. The apparatus was the same as used by Reynolds * in his viscosity experiments and is shown in fig. 4. Its reliability was proved by the good results it gave

Fig, 4.

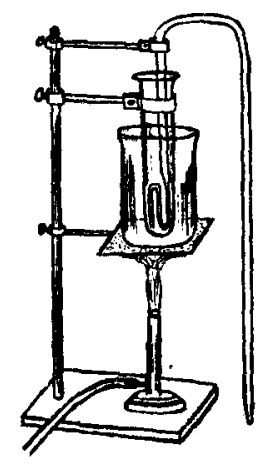

for water. The low temperatures in the experiments were obtained by means of a freezing-mixture of ice and sodium chloride. At the same time figures were obtained to show the variation of density with temperature of several solutions of different strengths. These figures are not given, but they were used to obtain for sodium chloride the curves shown in

* Scientific Papers, rol. ii. p. 239. 
figs. $5 \& 6$ (Pl. IV.), giving the relation between viscosity and temperature, and viscosity and density. The three upper curves in fig. 5 were for solutions of densities $1 \cdot 188,1 \cdot 146$, and 1.101 at a temperature of $13^{\circ} \mathrm{\%}$. The lowest curve is for water. In fig. 6 the curves shown are for temperatures $0^{\circ}$, $10^{\circ}, 30^{\circ}, 50^{\circ}$, and $100^{\circ} \mathrm{O}$. Figs. 7 and 8 give the same curves for calcium chloride. Straight lines were obtained for the logarithmic values plotted as in fig. 3 for each of the above temperatures. The values of " $n$ " for sodium chloride were found to be, when

$$
\begin{array}{ll}
\mathrm{T}=0^{\circ} \mathrm{C} ., & n=1 \cdot 48, \\
\mathrm{~T}=10^{\circ}, & n=1 \cdot 35, \\
\mathrm{~T}=30^{\circ}, & n=1 \cdot 10, \\
\mathrm{~T}=50^{\circ}, & n=1 \cdot 09, \\
\mathrm{~T}=100^{\circ}, & n=1 \cdot 075 .
\end{array}
$$

From these figures it appears that " $n$ " decreases proportionally to temperature from $0^{\circ}$ to $30^{\circ} \mathrm{C}$, but from there the relative diminution becomes much less up to $100^{\circ} \mathrm{C}$. Values of $\mu$ were calculated from these values of $n$ and were found to agree exceedingly well with the experimental values. It was desirable, however, to have a formula which would involve the three quantities $\mu, \rho$, and T. The above values of " $n$ " do not provide this, but it was found that, on assuming " $n$ " to vary regularly in values from $1 \cdot 4$ to 1.0 between the limits $0^{\circ}$ and $100^{\circ}$ C., a quite accurate formula was obtained in the form

$$
(\rho-1)^{1 \cdot 4-004 \mathrm{~T}}=\mathrm{A}\left(1-\frac{\mu^{\prime}}{\mu}\right) .
$$

The same procedure was gone throngh with the calcium chloride results. The values of " $n$ " here varied regularly from $\cdot 95$ to $\cdot 85$ as the temperature varied from $0^{\circ}$ to $50^{\circ} \mathrm{C}$. This gives as the best formula between these limits

$$
(\rho-1)^{\cdot 95-002 \mathrm{~T}}=\mathrm{A}\left(1-\frac{\mu^{\prime}}{\mu}\right) \text {. }
$$

To obtain the value of $A$ it is best to use the point at which the solution has its highest density. Otherwise, if $A$ be obtained from a low density point the liability to error in calculating the viscosities at higher densities is appreciable.

The variation of $A$ with $T$ was next noticed. 'The figures below give the actual values in each case for log. A. 
294 Mr. W. J. Walker : Relationship between Viseosity,

Sodium Chloride.

Actual values.

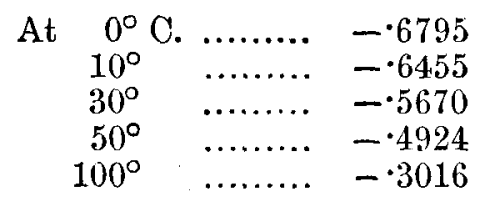

Calcium Chloride.

Actial values.

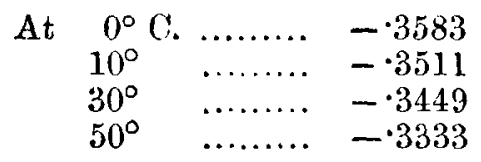

By readjusting these values so that $\log A$ may be regarded as a linear tunction of $\mathrm{T}$, formulæ were obtained for each of the solutions which gave a fairly accurate relation between $\rho, \mu$, and T. The readjusted values are :-

Sodium Chloride.

Readjusted values.

$$
\text { At } \left.\begin{array}{rrr}
0^{\circ} \mathrm{C} . & \ldots \ldots . . & -.6790 \\
10^{\circ} & \ldots \ldots \ldots & -.6416 \\
30^{\circ} & \ldots \ldots \ldots . & -.5716 \\
50^{\circ} & \ldots \ldots \ldots & -.4920 \\
100^{\circ} & \ldots \ldots \ldots & -.3050
\end{array}\right\} \log \mathrm{A}=-.6790
$$

Calcium Chloride.

Readjusted values.

$$
\text { At } \left.\begin{array}{rrr}
0^{\circ} \mathrm{C} . & \ldots \ldots . . & -.3580 \\
10^{\circ} & \ldots \ldots \ldots . & -.3530 \\
30^{\circ} & \ldots \ldots \ldots . & -.3430 \\
50^{\circ} & \ldots \ldots \ldots . & -.3330
\end{array}\right\} \log \mathrm{A}=-.3580
$$

The tables below give a comparison between the experimental and calculated values of $\mu$, according to the given formulæ

I. ...... $(\rho-1)^{1 \cdot 4-004 \mathrm{~T}}=\mathrm{A}\left(1-\frac{\mu^{\prime}}{\mu}\right)$ for sodium chloride.

II. ...... $(\rho-1)^{\cdot 95-002 \mathrm{~T}}=\mathrm{A}\left(1-\frac{\mu^{\prime}}{\mu}\right)$ for calcium chloride. 
Density, and Temperature of Salt Solutions.

I. Sodium Chloride.

\begin{tabular}{|c|c|c|c|c|c|c|c|c|c|c|}
\hline \multicolumn{2}{|c|}{$\mathrm{T}=0^{0}}$. & \multicolumn{2}{|c|}{$n=1 \cdot 4$} & $\mathrm{~T}=10^{\circ}$. & \multicolumn{3}{|c|}{$n=1 \cdot 36$} & \multicolumn{2}{|c|}{$T=30^{\circ}$} & 28 \\
\hline$\rho$. & $\mu_{e}$ & \multicolumn{2}{|c|}{$\mu_{c}$} & $\rho$. & $\mu_{e^{*}}$ & \multicolumn{2}{|c|}{$\mu_{c}$} & $\rho$ & $\mu_{e^{*}}$ & $\mu_{\sigma^{*}}$ \\
\hline $1 \cdot 19$ & $187 \cdot 0$ & \multicolumn{2}{|c|}{187.0} & $1 \cdot 18$ & 128.5 & \multicolumn{2}{|c|}{12766} & $1 \cdot 172$ & $74 \%$ & $73 \cdot 8$ \\
\hline $1 \cdot 15$ & $150 \cdot 0$ & \multicolumn{2}{|c|}{$150-5$} & $1 \cdot 15$ & 111.0 & & \multicolumn{2}{|c|}{$1 \cdot 15$} & 68 & $67 \cdot 1$ \\
\hline $1 \cdot 10$ & 122.0 & \multicolumn{2}{|c|}{$123 \cdot 3$} & $1 \cdot 10$ & $91 \cdot 5$ & & \multicolumn{2}{|c|}{$1 \cdot 10$} & 57 & $56 \cdot 2$ \\
\hline 1.05 & $107 \cdot 0$ & \multicolumn{2}{|c|}{$107 \cdot 6$} & $1 \cdot 05$ & $79 \cdot 1$ & & \multicolumn{2}{|c|}{1.05} & $50 \cdot 0$ & $48 \cdot 9$ \\
\hline & \multicolumn{4}{|c|}{$\mathrm{T}=50^{\circ} . \quad n=1.2$} & & $=1$ & . & & & \\
\hline & & & $\mu_{e^{*}}$ & $\mu_{c^{*}}$ & $\rho$ & & $\mu_{e}$ & & & \\
\hline & & & $47 \cdot 8$ & $47 \cdot 5$ & 1 . & & $21 \cdot 5$ & & & \\
\hline & & & $45 \cdot 0$ & $45 \cdot 0$ & 1. & & $18 \cdot 7$ & & & \\
\hline & & & $37 \cdot 9$ & $38 \cdot 4$ & 1 . & & $16^{*} 6$ & & & \\
\hline & & & $34 \cdot 0$ & $34: 0$ & & & & & & \\
\hline
\end{tabular}

II. Calcium Chloride.

\begin{tabular}{|c|c|c|c|c|c|}
\hline \multicolumn{3}{|c|}{$\mathrm{T}=0^{\circ}$} & \multicolumn{3}{|c|}{$\mathbf{X}=10^{\circ} . \quad n=.93$} \\
\hline$\rho$. & $\mu_{e}$ & $\mu_{c^{*}}$ & $\rho$. & $\mu_{e}$ & $\mu c^{\circ}$ \\
\hline 1.277 & $310^{\circ} 0$ & $308 \cdot 0$ & $1 \cdot 30$ & $273 \cdot 0$ & 277 \\
\hline $1 \cdot 200$ & $200 \cdot 0$ & $198^{\circ} 0$ & $1 \cdot 20$ & 1455 & 148.0 \\
\hline $1 \cdot 10$ & $136 \cdot 0$ & $134 \cdot 5$ & $1 \cdot 10$ & $99 \cdot 0$ & $99 \cdot 8$ \\
\hline 1.05 & $116 \cdot 0$ & 115.5 & $1 \cdot 05$ & $84 \cdot 0$ & $85 \cdot 2$ \\
\hline \multicolumn{3}{|c|}{$\mathrm{T}=30^{\circ}$} & \multicolumn{3}{|c|}{$\mathrm{T}=50^{\circ} . \quad n=\cdot 85$} \\
\hline 1.293 & $177 \cdot 0$ & $172-5$ & $1 \cdot 30$ & 137.0 & 1370 \\
\hline $1 \cdot 20$ & $96 \cdot 4$ & $94 \cdot 8$ & $1 \cdot 20$ & $69 \cdot 0$ & $68 \cdot 7$ \\
\hline $1 ‘ 10$ & $63 \cdot 0$ & $62 \cdot 8$ & $1 \cdot 10$ & $45 \cdot 0$ & $44 \cdot 7$ \\
\hline 1.05 & $53 \cdot 0$ & $53: 2$ & 1.05 & $37 \cdot 5$ & $37 \cdot 4$ \\
\hline
\end{tabular}

Here $\mu_{e}=$ experimental value of $\mu_{.} \quad \mu_{c}=$ calculated value of $\mu$. 
From these tables it appears that the greatest difference between experimental and calculated values occurs at about $30^{\circ}(\mathrm{G}$, but the differences (a little over 2 per cent. being the greatest) are not great when one considers the experimental difficulties involved in the measurement of viscosity.

Several other figures for different salts were taken from the Smithsonian Tables and the log. graphs plotted, and in no case was there any great deviation from the strayht line. Unfortunately, lowever, in the majority of cases only three points are obtainable from the given figures, so that the comparison with these other solutions is not so rigid as is desirable. Again, some of the solutions actually diminish in viscosity as salt is added until a certain minimum viscosity is attained, after which the viscosity increases regularly with an increase of density as in the majority of solutions. One of the most noteworthy examples of this behaviour is found in ammonium nitrate, the density-viscosity curve of which is shown in fig. 9 (Pl. IV.). It might be thought that such a case would form a departure from the above law. It is found, however, that on giving the formula the form

$$
\pm(\rho-x)^{n}=\mathrm{A}\left(1-\frac{\mu^{\prime}}{\mu}\right)
$$

where $\mu^{\prime}$ is the minimum viscosity, and where the negative sign is used when $x$ is greater than $\rho, x$ being the density at the minimum viscosity point, then the law does hold very approximately. Five points are given in the case of ammonium nitrate, and on plotting the log. graph for these, they were found to lie very sensibly on a straight line as shown in fig. 10. The same thing is shown in fig. 10 for manganese chloride for which four points are given in the tables, the $\log$. graph of these also being practically a straight line. Manganese chloride, however, does not have a minimum viscosity point but behaves like the majority of salts.

The reason for the difference in the value of " $n$ " for sodium chloride as found in the two experiments * lies, of course, in the different conditions under which these were carried out, the solutions in the first set of experiments being unfiltered.

If this law holds generally for all salt solutions, as seems ptrobable, the best method of obtaining the formula for each salt would be to make three accurate decerminations (at the same temperature) of the viscosity and density at points as far apart as possible and deduce the value of " $\log A$ " and

$$
\text { * Pp. } 202 \text { \& } 203 .
$$


" $n$ " therefrom. This may be repeated for say another two temperatures, and thus the variation of " $\log A$ " and " $n$ " with temperature can be ascertained. The formula may then be completed.

One reason for the diminution of " $n$ " with temperature may be stated as follows. At the higher temperatures the fluidity of the solvent is increased. Now the behaviour of the solute is found to be in many ways analogous to that of a gas. This analogy would apparently become more pronounced the higher the temperature, i.e. the greater the fluidity of the solvent, for then the particles of solute could move about with greater freedom. The viscosity of a gas is known to be independent of density, and on glancing at figs. 6 and 8 we see that the higher the temperature the less pronounced becomes the increase of viscosity due to the increas: of density. This is specially evident in the case of sodium chloride at $100^{\circ} \mathrm{C}$.

It may be of interest to note here that the same method of plotting was used to determine if $\mathrm{F}(\mu)$ in the formuia

$$
F(\mu)=a-\frac{b}{\mathrm{~T}}
$$

was of the form $(\mu)^{n}$.in the cases of water and mercury。 It was found not to be so, so that some other form must be ascribed to this function in the case of these two substances at least.

In conclusion, I desire to express my thanks to Professor Gibson for the encouragement he gave me during the course of the work.

XXXIII. The Electrification at Liquid-Gas Surfaces. By H. A. M'TagGarT, M.A. Toronto; Research Student of Gonville and Caius College, Cambridge*.

W

HEN a liquid in the form of drops falls through a gas and splashes against an obstacle it is found to be electrified. At the same time the gas acquires a charge of the opposite sign. This charge found on the liquid varies with the liquid, the gas through which it falls, the nature of the obstacle on which it strikes, and the force of the impact. 'To account for this electrification it is usually supposed that at the surface of separation between the liquid and the gas, a double layer is formed, the two surfaces of which are

* Communicated by Prof. Sir J. J. Thomson, O.M., F.R.S. 


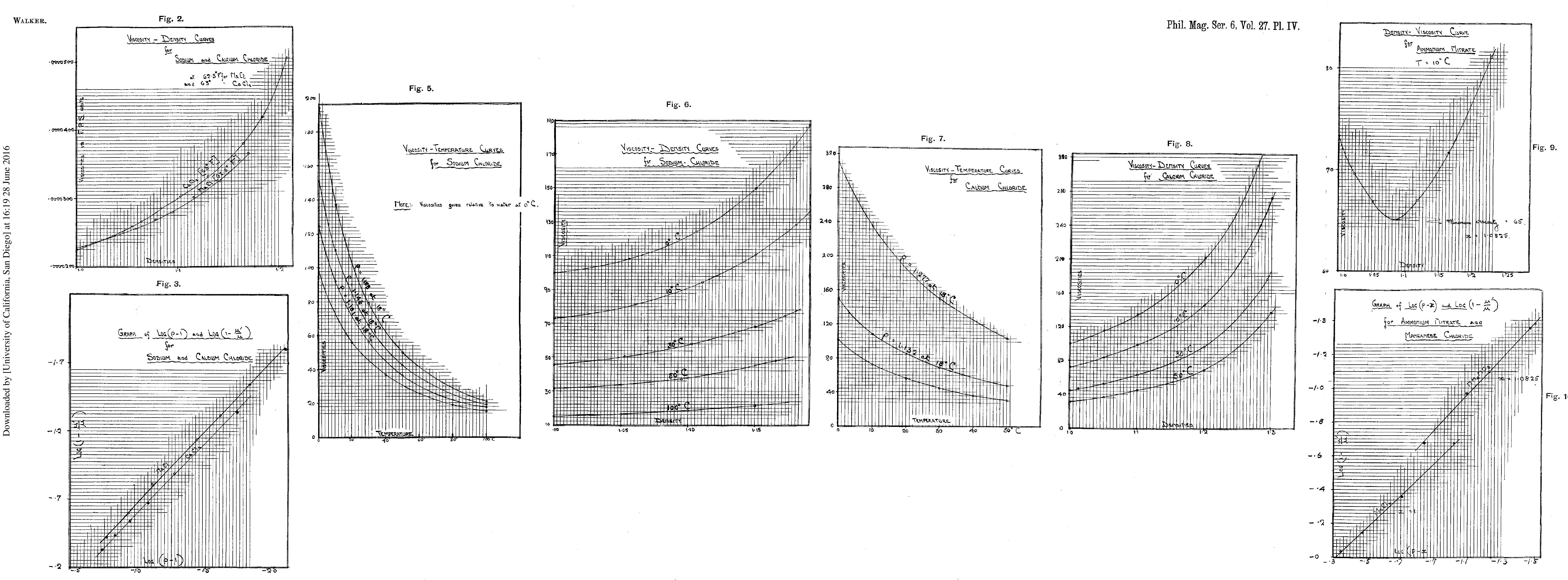

